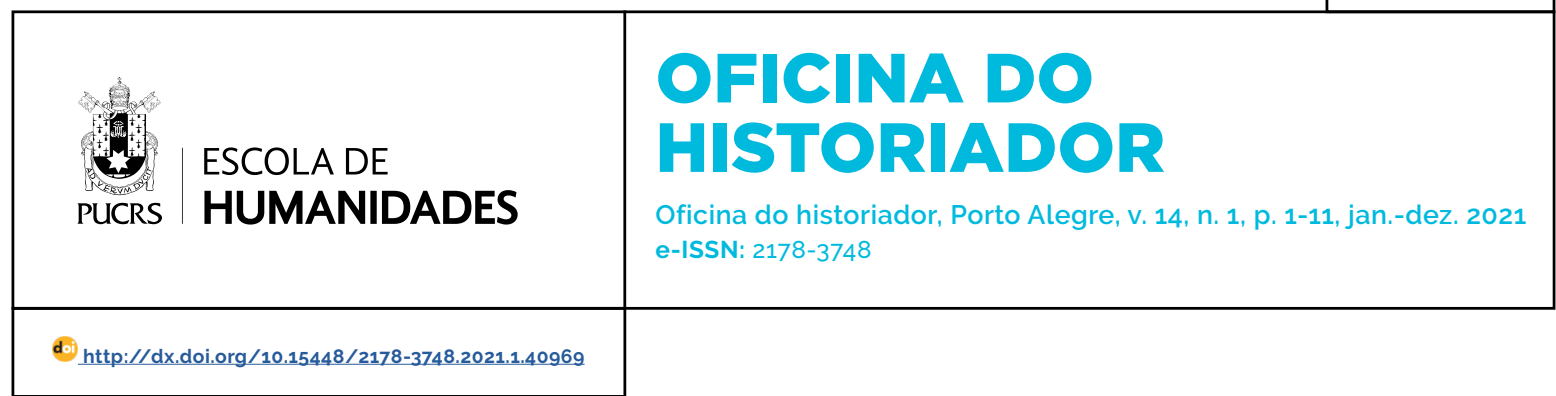

SEÇÃO: ARTIGOS

\title{
O canto e a vida das quebradeiras de coco do Maranhão
}

The singing and the life of the coconut breakers of Maranhão

\section{Raimundo Lima dos \\ Santos ${ }^{1}$}

orcid.org/0000-0001-5242-580X

raimundosantos81@gmail.com

Recebido em: 21 mai. 2021. Aprovado em: 08 set. 2021. Publicado em: 14 dez. 2021.
Resumo: Este trabalho analisa o universo sociocultural das "quebradeiras" de coco babaçu do Maranhão, através de uma coletânea de cantos, para tentar entender por outro prisma alguns elementos que compõem suas visões de mundo. Para tanto, faz uma leitura histórica sobre a organização sociopolítica dos grupos de mulheres no território maranhense, nas últimas décadas. Em seguida, o texto se debruça sobre as músicas, compiladas em um livro, intitulado Canto e encanto nos babaçuais. Músicas sob dominio popular selecionadas por 'As Encantadeiras..... Um dos principais objetivos é buscar nos cantos as expressões de sua vida e de seu cotidiano, assim como entender a forma como elas leem o mundo e sua própria realidade. Nesse sentido, as canções, não são apenas manifestações artísticas, separadas da própria vida. Assim, faz-se uma leitura dessas composições, na tentativa de revelar mais sobre o mundo dessas mulheres, alcançar o que se pode chamar de "pontos cegos", os elementos não intencionais de suas expressões. Dessa forma, tentar compreender melhor o cotidiano, as crenças, os medos e as perspectivas de vida desse grupo social. A arte, no que tange a literatura, é mais que um meio para se distrair, pois ela pode revelar mundos ocultos e os reconstruir.

Palavras-chave: Cantos. Quebradeiras de coco. Maranhão.

Abstract: This work analyzes the sociocultural universe of the babassu coconut "quebradeiras" in Maranhão, through a collection of songs, in an attempt to understand from another perspective some elements that make up their views of the world. Therefore, it makes a historical reading of the sociopolitical organization of women's groups in Maranhão territory in recent decades. Then, the text focuses on the songs, compiled in a book, entitled "Canto e enchantment in babaçuais. Popular songs selected by 'As Encantadeiras'...". One of the main goals is to seek expressions of their life and daily life in the corners, as well as understanding how they read the world and their own reality. In this sense, songs are not just artistic manifestations, separate from life itself. Thus, there is a reading of these compositions, in an attempt to reveal more about the world of these women, reaching what might be called "blind spots", the unintentional elements of their expressions. Thus, trying to better understand the daily life, beliefs, fears and life perspectives of this social group. Art, literature is more than a means of distraction, as it can reveal hidden worlds and reconstruct them.

Keywords: Corners. Coconut breakers. Maranhão. 


\section{Introdução}

No século XX, a história se consolidou no diálogo com outras disciplinas, isso provocou mudanças filosóficas e metodológicas. Elas se alinharam na diversidade de temas e de abordagens e trouxeram novas questões, que não poderiam existir sem esse movimento. Talvez uma das principais mudanças na historiografia atual envolva a noção de verdade, cada vez mais plástica e menos ambiciosa, embora não menos importante.

Na medida em que a história dialoga com a arte, com a música, com a fisica, com a literatura ou qualquer outro ramo do conhecimento, ela se volta para diferentes indagações e compreende verdades distintas das formas convencionais. Ao dialogar com a literatura, há a possibilidade de explorar novos caminhos e novas descobertas e, assim, oferecer outras perspectivas ao conhecimento. Em um cenário de múltiplas verdades, não há a ambição de um fato universal, apenas o anseio de uma verdade possivel.

Os fatos são também construções sociais e a relação das fontes com as explicações é elaborada dentro de amarras na visão de mundo do historiador. O que se escolhe e o que se descarta depende também da relação com o lugar social, condicionantes institucionais às quais todos estão, em alguma medida, sujeitos. Nesse sentido, afirma Michel De Certeau (2002, p. 66),

[...] Encarar a história como uma operação será tentar, de maneira necessariamente limitada, compreendê-la como a relação entre um lugar (profissão), procedimentos de análise (uma disciplina) e a construção de um texto (uma literatura). É admitir que ela faz parte da "realidade" da qual trata, e que essa realidade pode ser apropriada "enquanto atividade humana", "enquanto prática" [...].

Para Carlo Ginzburg (1989, p. 177) todo texto possui elementos incontrolados, pois, muitas vezes, as ideias secundarizadas pelos autores são as mais reveladoras de suas intenções ocultas, enquanto as centrais são escolhidas para veicular a mensagem desejada. Nesse sentido, "Se a realidade é opaca, existem zonas privilegiadas - sinais, indicios, que permitem decifrá-la".

Esse autor busca uma "realidade às avessas", pois parte de zonas tangenciais do texto para alcançar um tipo de compreensão que não é secundária, como na psicanálise, ao buscar em "atos falhos" a compreensão de certos aspectos da personalidade. Essa maneira de entender autores e textos investiga atos involuntários para compreender percepções densas sobre determinados indivíduos ou grupos. "Escavando os meandros dos textos, contra as intenções de quem os produziu, podemos fazer emergir vozes incontroladas" (GINZBURG, 2007, p. 11). Essa busca, no entanto, não precisa descartar os elementos explícitos e intencionais do texto, pois elas podem se complementar.

Ler os testemunhos históricos contra as intenções dos próprios autores pode ser um exercicio fecundo para alcançar outros graus de compreensão, não necessariamente melhores, mas indispensáveis para se perceber outros pontos de vistas. Assim como as pessoas, os textos revelam mais do que aquilo que está na superfície das intenções.

Ao percorrer esse caminho, procura-se, neste trabalho, ver as "quebradeiras" de coco por meio de seus cantos, abarcados aqui no rol de uma produção literária. Aqui entende-se literatura no seu conceito mais amplo, da produção de texto, ficcionais ou não, ajustados pela criatividade. Por meio de versos, escritos ou cantados, é possivel encontrar pistas de um grupo de pessoas, de uma comunidade ou de um individuo. Busca-se aqui por percepções econômicas, políticas e culturais, assim como por fatores aparentemente secundários, mas que podem ser de grande importância para o entendimento desses grupos de mulheres.

\section{A vida}

Desde o periodo colonial, a palmeira do babaçu, Orrbignya speciosa, beneficia as populações rurais do Maranhão e, no século XX, o fruto ganhou destaque na indústria do estado. $O$ coco babaçu pode ser encontrado em alguns paises da América, a exemplo do México, da Bolivia e Colômbia. No Brasil, há incidência nos estados de Minas Gerais, Mato Grosso, Pará, Tocantins e Piauí, mas é no Maranhão que se encontra a 
maior cobertura vegetal, pois cerca de $25 \%$ do seu território é coberto por florestas de babaçu (SANTOS, 2010, p. 98).

As primeiras organizações femininas no Maranhão começaram na região do Médio Mearim, na parte central do estado. Essa região contém a maior floresta de babaçuais do estado e por muitos anos liderou as estatísticas dos conflitos sociais vinculados à concentração fundiária (SANTOS, 2010, p. 122). Essas tensões sempre estiveram relacionadas à falta do acesso à terra para a pequena lavoura e, depois, a impossibilidade de alcance ao coco babaçu, importante componente na renda e na vida de muitas famílias maranhenses.

Na década de 1970 começou uma significativa transformação nas relações sociais e econômicas na região do Mearim. Esse divisor de águas se impôs com as restrições impostas por fazendeiros às quebradeiras de coco aos babaçuais. De acordo com Barbosa (2008, p. 5), o capim para a pecuária tomou o lugar de florestas de babaçu, com isso, o acesso ao fruto teria se tornado mais dificil. Foi nesse momento que os grupos femininos começaram a se mobilizar para impor uma resistência aos fazendeiros. Na década seguinte, começaram a surgir clubes de mães, associações e outras agremiações em defesa dos babaçuais e seu aproveitamento sustentável (AYRES JÚNIOR, 2007, p. 118).

As mulheres criaram um grupo de estudos do babaçu com a proposição de medidas alternativas para o aproveitamento do fruto. A Associação Maranhense dos Trabalhadores Rurais (AMTR) desenvolveu a produção de sabonetes do óleo do coco. A produção, ainda que em pequena escala, ganhou o mercado europeu (AYRES JÚNIOR, 2007, p. 118). Desde então, além do sabonete, a entidade produz o óleo corporal e tem a parceria de dezenas de outras associações em diferentes municípios da região.

Outra importante organização fundada no fim da década de 1980 foi a Associação em Áreas de Assentamentos do Maranhão (ASSEMA). Essa é uma das principais organizações em defesa de trabalhadores e trabalhadoras rurais e extrativis- tas do estado. A entidade é constituida por várias associações, sindicatos e cooperativas (BARBIERI, 2004, p. 60). Soma-se a ela, no grupo das entidades mais importantes, a Cooperativa de Pequenos Agricultores de Lago do Junco (COOPALJ). Essa se especializou na extração do óleo de babaçu, para fins alimentícios. Assim como a MMTR, ela alcançou o mercado externo. Outras organizações de menor porte, em diferentes regiões do estado, se dedicaram a diversos subprodutos do coco babaçu, a exemplo do artesanato e da farinha de mesocarpo, extraída da casca.

No início da década de 1990, surgiu a mais importante organização política das quebradeiras, o Movimento Interestadual das Quebradeiras de Coco Babaçu (MIQCB). Além da atuação propriamente política, o movimento tem importante papel econômico, ao dar suporte na venda dos produtos das mulheres. A entidade é composta por trabalhadoras do Maranhão, Piauí, Pará e Tocantins e contou, inicialmente, com apoio financeiro da União Europeia (ALMEIDA, 2000).

Por meio dessas organizações, as quebradeiras de coco conquistaram um importante espaço político na região. Com a conquista desse lugar de fala, sua voz em defesa do ambiente, dos babaçuais, do seu aproveitamento integral e de melhores condições de vida, passou a ecoar com mais intensidade. Essa voz ressoou para todas as direções, graças ao apoio de organizações interestaduais e internacionais, bem como a adesão de políticos, além da conquista de espaço na mídia. Em consequência disso, boa parte da sociedade brasileira conhece os problemas dessas mulheres, suas lutas e aspirações.

As quebradeiras de coco do Maranhão, além de buscarem melhores condições de vida com o fruto, querem mostrar que os valores tradicionais comunitários, em harmonia com o ambiente, podem sobreviver, ao menos em parte, atualmente. Por isso, a luta desses grupos é mais ampla do que supõe um olhar apressado. É uma batalha de valores, de visões de mundo, em que elas esperam influenciar a sociedade de alguma forma.

Para entender melhor a luta dessas mulheres do coco, é preciso conhecer quem são elas e uma 
forma de fazê-lo é observar suas manifestações culturais. Elas têm o costume de cantar enquanto se destinam ao trabalho cotidiano nos cocais e, as canções, expressam seu cotidiano, suas lutas e, dentre outros aspectos, sua visão de mundo. Dessa forma, é possivel entender melhor suas vidas no sentido coletivo e privado.

\section{O canto}

O canto, música ou verso, faz parte da vida das quebradeiras de coco, ele as acompanha logo ao nascer do dia, quando muitas vão aos cocais, antes que o incômodo do sol arrebate as terras maranhenses. Ao começar cedo, podem estar em casa antes do meio-dia para o almoço com a família. A depender do lugar, o cocal pode estar no "quintal" de casa, mas o comum é uma caminhada de alguns ou vários quilômetros para a coleta do fruto.

Durante esse percurso aos babaçuais ou no trabalho, elas cantam as músicas ensinadas pelas mães e avós ou fazem suas próprias, também passadas às filhas e netas. Essas canções expressam muitos sentimentos, medos, insatisfações ou podem celebrar a alegria de ter saúde e alimento. Conforme a região e suas variantes culturais, os cantos pedem chuva, nos tempos de seca, sol em tempo de chuva, amores perdidos ou, dentre outros desejos, abrigo em outra vida para as almas que deixam esse mundo.

Cada lugar tem suas próprias canções, que se somam às de outras localidades. Para reunir todos esses cantos seria necessária uma pesquisa extensa em vários municípios maranhenses e em outros estados. Para uma amostra significativa, este trabatho se utiliza de um livro intitulado Canto e encanto nos babaçuais: músicas sob dominio popular selecionados por "As encantadeiras", lançado em 2014. A obra contém 44 músicas, de diferentes regiões.

Por ter a colaboração da Assema, Capes, Museu Emilio Goedi, UFPA, Universidade do Estado do Amazonas, dentre outros colaboradores, é natural que o repertório do livro tenha a necessidade de expressar elementos políticos e culturais de interesse dessas entidades. Mesmo assim, o livro não perde a feição das próprias mulheres, visto que os cantos, em sua maioria, são compostos por elas.

O repertório não tem precisão geográfica, essas músicas podem ser conhecidas no Maranhão, Pará e Tocantins ou apenas em um desses estados. O mais importante para este trabalho é saber que elas pertencem ao universo das quebradeiras de coco, em especial as maranhenses.

O MIQCB, composto por trabalhadoras extrativistas de quatro estados, contribuiu para formar o grupo "As encantadeiras", com a participação de mulheres oriundas de várias regiões. Esse coletivo feminino já se apresentou em desfile de carnaval na capital maranhense, no Palácio do Planalto, no Encontro Mundial de Comunidade do Alimento, na Itália, e em dezenas de outros eventos regionais, nacionais e até fora do País. O livro pode ser resumido da seguinte maneira:

\begin{abstract}
Com músicas que traduzem suas vidas e trabalhos como mulheres, as quebradeiras de coco utilizam o seu canto e seus encantos para expressar o valor do seu trabalho na agricultura e extrativismo do babaçu e na luta pela terra e pelo livre acesso aos babaçuais. Assim, esse livro surge do desejo das mulheres quebradeiras de coco compartilharem suas músicas com crianças, jovens e adultos de suas comunidades tradicionais (AS ENCANTADEIRAS, 2014, p. 5).
\end{abstract}

Influenciado por seus organizadores, o livro expressa uma mensagem polissêmica com alcance na política, no ambiente e na cultura. Além disso, chama atenção para os problemas vividos por comunidades extrativistas, suas dificuldades e suas aspirações. Contudo, quem canta os sentimentos, as dores e as alegrias são as mulheres camponesas que vivem em busca de sonhos singelos, voltados ao sossego do lar, à família e aos amigos, em simbiose também com seu meio natural.

Esses cantos expressam diferentes valores, uma parte deles coletivo e outra individual, uma parte consciente, outra inconsciente. À medida que se percorre os cantos, encontra-se uma interação, um diálogo do texto com a vida, de modo a entender que os dois são inseparáveis e podem ser compreendidos um através do outro. 


\section{Aspectos econômicos}

Na parte econômica, pode-se ver como a vida dessas mulheres está estruturada em uma realidade de pobreza e de dificuldades diversas. Na falta de dinheiro, as dezenas de subprodutos do babaçu são indispensáveis para a vida nessas comunidades. "O coco é para nós grande riqueza, / é obra da natureza,/ ninguém vai dizer que não./ Porque da palha se faz casa pra morar,/já é um meio de ajudar a maior população". (AS ENCANTADEIRAS, 2014, p. 8-9).

O óleo do coco é muito utilizado no preparo de alimentos, na produção de sabão e na venda in natura. "Se faz o óleo pra temperar comida,/ é um dos meios de vida pra os fracos de condição./ Reconhecemos o valor que o coco tem, / a casca serve também para fazer o carvão" (AS ENCANTADEIRAS, 2014, p. 8-9). Além disso, da palha, o artesanato, do caule da palmeira, o adubo. O próprio coco pode ser vendido com as amêndoas extraídas, o que também contribui para a renda. Todos esses produtos têm a importância de substituir ou, com a venda, comprar produtos do supermercado.

Elas compreendem, ainda que algumas vezes de forma intuitiva, que a diferença de valor entre seus produtos e os do mercado se organiza em uma relação de genuína desigualdade de classe ou de grupo. Diz um canto (AS ENCANTADEIRAS, 2014, p. 20-21): "Eu sou roceiro, vivo de cavar o chão,/ Tenho as mãos calejadas, sim senhor,/ Me falta terra, falta casa, falta pão". Quando dizem "só tenho a enxada e um título de eleitor", é porque compreendem que essa desigualdade não é espontânea, pelo contrário, se organiza em uma relação estruturada para esse fim. Esse é um dos motivos que levam populações inteiras a se deslocar em busca de um pedaço de terra para viver. Para muitos moradores de zonas rurais, em especial do Maranhão, a falta de instrução formal e qualificação técnica fez da terra a única forma de viver.

Boa parte da população maranhense é reflexo de migrações, de pessoas que abandonaram seus lares, em diferentes partes do Nordeste, devido à seca e por causa da fome. Vieram para cá na intenção de realizar o sonho de uma vida melhor, conforme poema a seguir (AS ENCANTADEIRAS, 2014, p. 23):
Eu vim de longe, pra encontrar o meu caminho, tinha um sorriso e o sorriso ainda valia. Achei difícil a viagem até aqui, mas eu cheguei, mas eu cheguei. (2x)

Eu vim depressa, eu não vim de caminhão, eu vim a jato, neste asfalto, neste chão. Achei difícil a viagem até aqui, mas eu cheguei, mas eu cheguei. (2x)

Eu vim por causa daquilo que não se vê, Vim nu, descalço, sem dinheiro e na pior. Achei difícil a viagem até aqui, mas eu cheguei, mas eu cheguei. (2x)

Eu tive ajuda de quem você não acredita, tive esperança de chegar até aqui. Vim caminhando, aqui estou.

Me decidi: eu vou ficar, eu vou ficar. (2x).

Muitas famílias continuaram a migração para fugir dos conflitos e conquistar um pedaço de terra para cultivar. Em muitos casos, essas constantes migrações não surtiram o efeito esperado, pois em todos os lugares havia conflitos agrários. As terras cobertas por babaçuais, lagos e rios nem sempre foram "terras prometidas". Os conflitos com fazendeiros e grileiros impedia essa paz. "Do vale do Mearim, eu corri pro Pindaré./ Quando eu olhei pra trás,/ O bicho vinha no meu pé./ Da região do Tocantins, fui parar no Araguaia./ Quando eu chegava lá, O bicho tava na tocaia" (AS ENCANTADEIRAS, 2014, p. 24). Esse bicho metafórico, o fazendeiro, marca a vida de muitas familias no Maranhão.

Tais conflitos são causa e efeito das dificeis condições de vida de muitas familias desamparadas. As roças, os rios para a pesca e os babaçuais são de grande importância, para atenuar a falta de dinheiro.

Nessas condições, ainda que o babaçu tenha grande importância para as familias nos cocais, por conta das dificuldades de acesso ao fruto, pelas distâncias e pelas restrições de donos de terra, é preciso buscar outras formas de ganho. A roça de arroz, feijão, milho, dentre outros produ- 
tos, garante o alimento básico de muitas pessoas. Trabalhos braçais no campo e na cidade são uma alternativa aos homens e mulheres. Mesmo que o ganho seja uma "mixaria", as mulheres colocam a trouxa de roupas na cabeça e descem para o rio. "[...] O sol quente na cabeça, ô ô ô!/ E os pés na água fria ô ô ô!/ É a mulher lavadeira, trabalha a semana inteira,/para poder ganhar a vida [...]" (AS ENCANTADEIRAS, 2014, p. 11). Apesar das dificeis condições, quando elas ganham algum dinheiro com o coco, vem a alegria e o otimismo.

Na década de 1970 essas mulheres e seus esposos começaram a se organizar em sindicatos e associações, pois entendiam que a realidade de miséria e exclusão passava por decisões políticas. Esses conflitos, ocasionados pela resistência aos fazendeiros resultaram em mortes e perseguições. Com o tempo muitos líderes sindicais foram mortos, presos ou foragidos.

A mulher, em casa com os filhos, recebia as intimações, as cestas básicas da Igreja e os convites para participar de reuniões no sindicato. Com o tempo elas deixaram de ser apenas representantes dos homens e assumiram o protagonismo de uma luta política. Com essa mudança de protagonismo, a luta mudou seu formato. Ao invés da reivindicação da terra, apenas o acesso aos babaçuais, cercados pelos fazendeiros; em lugar do conflito armado, o convencimento; ao contrário do fogo na roça, a preservação das florestas.

\section{Aspectos políticos}

Os cantos expressam perspectivas políticas em um horizonte de longo prazo, a qual anseia uma transformação mais profunda da sociedade. Além disso, tratam dos problemas mais imediatos da política local ou regional. A primeira vertente expressa os ensinamentos nas lutas sindicais e demais associações de classe, focada em uma grande transformação social, com base em principios de igualdade. A segunda está mais associada a desejos e necessidades da vida cotidiana. Essa tem inspiração empirica e é de mais fácil compreensão pela maioria das pessoas, quebradeiras de coco, lavradores e demais seguimentos afins.

Diz um canto (AS ENCANTADEIRAS, 2014, p.
3): "Mulher frágil era um ditado, pra menos te tornar./ Mas quem viu a revolução, sem a mulher funcionar?". Em uma compreensão clássica, toda grande transformação começa com uma mudança no pensamento, na mentalidade coletiva. A estrofe seguinte do verso afirma que as mulheres precisam se libertar de concepções que as aprisionam em uma percepção de inferioridade e diz que o jeito feminino de criar é necessário para mudar o mundo.

O verso continua e conclama as mulheres a se expressarem, abrirem a boca, na linguagem coloquial, para equilibrar o diálogo. Ao afirmarem que "é preciso temperar", estão reivindicando esse espaço de fala das mulheres, que antes de serem dominadas por um sistema econômico, estão subjugadas por um sistema cultural, onde o machismo aprisiona as mulheres na coadjuvação do lar. Esse rompimento só ocorrerá quando elas deixarem de esperar e fizerem sua parte, lembra o verso. Esse equilibrio ou tempero é necessário, pois "I...] O prato da vida é insosso, sem o sal do teu falar!" (AS ENCANTADEIRAS, 2014, p. 11).

É preciso lutar para que o processo de mudança social ocorra mais rápido. Não será fácil, a luta exige sacrificios e perdas. "O sangue será semente", as vidas perdidas, pensam, serão lembradas e darão lugar a outras na luta. A canção lembra que o povo sabe o que quer, a resistência nos conflitos agrários é resultado da consciência de uma classe explorada.

Contudo, outra canção (AS ENCANTADEIRAS, 2014, p. 13) lembra que além do sangue derramado, é preciso derramar o amor. A Igreja Católica teve destacada importância na organização de movimentos sociais no Brasil e no Maranhão. Uma das influências desse legado é o ensinamento do amor cristão, mesmo com os inimigos. É importante ter "o coração cheio de amor", ainda que o processo de disputa por terra e o acesso aos cocais seja permeado por violência fisica e simbólica.

A luta vem do desejo de mudança, ou da inevitabilidade do conflito. "Não tenho mais para onde ir, todo lugar o bicho tá./ Não vou mais sair daqui,/ Não vou caçar outro lugar!" (AS ENCANTADEIRAS, 2014, p. 24). As organizações sindicais 
no Maranhão surgiram com essa inevitabilidade. A AMTR é uma das principais entidades do estado em favor de agricultores e extrativistas, graças a ela, as quebradeiras tiveram mais força para defender os babaçuais. Uma canção (AS ENCANTADEIRAS, 2014, p. 41) é dedicada a esta organização, ao dizer como ela ajuda as mulheres a desenvolverem produtos para o mercado.

O canto "Samba das quebradeiras" (AS ENCANTADEIRAS, 2014, p. 27) diz que nasceu um projeto e um sonho se concretizou. Certamente foi somente após as mulheres terem se organizado que sua voz, seus ideais e seus produtos ganharam um espaço fora de seus próprios povoados. Alcançaram diferentes localidades do Brasil e até da Europa.

Mesmo com o aprendizado político nas associações e sindicatos sobre uma revolução, liderada pelos excluidos, a vida dessas mulheres está permeada pela realidade imediata da política local. É essa que define cotidianamente seu trabalho, seu sustento e sua vida. Pode não haver dúvidas que uma profunda transformação social ocorrerá algum dia, mas é inevitável pensar e lutar hoje. "Mulher parada, deixa de ser tão medrosa!/ Seja um pouco corajosa, segura na minha mão./ Lutemos juntas com coragem e com amor,/ pra o governo dar valor a esta nossa profissão" (AS ENCANTADEIRAS, 2014, p. 8-9). Se elas não conquistarem seus direitos, pensam, haverá uma perda não apenas para as quebradeiras, mas para toda a sociedade.

Em termos locais, as músicas expressam a velha relação entre políticos e eleitores. Nela há um interesse momentâneo em tempos de eleição, após isso, a parte mais pobre da sociedade não vê os benefícios da política. As quebradeiras entram nesse grupo, pois "Só tem um título e uma machada". Dessa forma, assim descrevem alguns politicos locais (AS ENCANTADEIRAS, 2014, p. 17):

Deixa esse bicho, não traz o bicho pra cá. Larga esse bicho, deixa o bicho se virá. Mata esse bicho, que o bicho quer te matar. Pelo que o bicho me disse, tá querendo te enrolar.

[...]

\begin{abstract}
Trabalhei muito para fazer um prefeito, para ver se havia um jeito da minha vida melhorar.

Mas o individuo quando está no palacete, no pobre mete o cacete, com força para matar. [...].
\end{abstract}

Uma canção (AS ENCANTADEIRAS, 2014, p. 18) fala dos efeitos de escolhas políticas. O dinheiro destinado à saúde não se converte em benefícios às populações extrativistas. "Nosso povo tá doente", diz o verso, mas nada acontece no poder público, apesar dos altos impostos. Elas sabem que só a pressão social pode impedir que o povo não "morra à míngua". É preciso combater, conclama a canção, pois foi assim que conseguiram ampliar suas forças enquanto movimento social.

A descrença se revela em todas as instâncias da política, local ou nacional. Em suas casas de taipa, elas escutam o rádio e as notícias falam de reforma agrária, uma espera longa, paleada por "Falsos projetos pra poder me tapear". Para elas, a cidadania passa por uma vida digna, com trabalho, lazer, saúde, educação, dentre outros aspectos. Muitas familias dos cocais passam longe disso, por isso, diz o verso, "sou brasileiro só na hora de votar" (AS ENCANTADEIRAS, 2014, p. 20-21).

O mesmo canto expressa a descrença em determinados políticos. "Sou sismado com um grão de traição", isso pode expressar uma traição a cada dois ou quatro anos. Alguns fogem dos "rostos lisos", mas outros são "comprados por cem gramas de sorriso" (AS ENCANTADEIRAS, 2014, p. 20-21). Nesse caso, há uma fraqueza no povo, o coração bom, que perdoa e esquece as mentiras. Esse problema, pensam, contribui para perpetuar as desigualdades e as injustiças.

Nas organizações, as mulheres se tornam mais fortes e mais esclarecidas. Quanto mais atomizadas, menos valor e menos força política, em consequência menos mudanças. "Nós descobrimos o valor da união, / que é arma poderosa e derruba até dragão!/ E já sabemos que a riqueza do patrão/ E o poder dos governantes passa pela nossa mão!" (AS ENCANTADEIRAS, 2014, p. 39). 
Tudo passa pela política, enquanto uns ganham milhões, o povo vive de tostões, diz o verso.

Quando as quebradeiras de coco começaram a ter protagonismo político há algumas décadas, as lutas sociais ganharam tonalidades próprias. Um caráter mais pacifico prevaleceu, ainda que o embate direto ocorra constantemente. Uma identidade feminina se impôs no modo de fazer em todas as esferas. Na política, o mesmo ocorrerá, novas práticas surgiram.

Além do engajamento em associações, clubes de mães e sindicatos, as quebradeiras de coco entenderam a importância de sua mobilização na política partidária. Elas levaram a proposta de lei do "Babaçu Livre" ao Congresso Nacional. Lá não teve apoio suficiente para ser aprovada. A garantia da propriedade privada se sobrepôs à liberdade dos babaçuais para as quebradeiras. Pela proposta elas poderiam entrar nas fazendas para colher o coco. No estado do Maranhão, essa lei foi aprovada no municipio de Lago do Junco em 1997, cinco anos depois em Imperatriz. Ao todo, seis municipios no Maranhão aprovaram a lei, dois no Pará, dois no Tocantins e um no Piauí (ANTUNES, 2006, p. 124).

Ainda que haja problemas na efetivação da Lei, isso mostra que essas mulheres organizadas foram mais longe do que muitos esperavam. "Essa luta não é fácil,/Mas vai ter que acontecer!/ As mulheres organizadas,/ tem que chegar ao poder!" (AS ENCANTADEIRAS, 2014, p. 13). No aspecto político-partidário, elas procuram se aliar com vereadores, prefeitos, deputados e senadores que apoiam sua causa. No Mearim, elegeram a primeira vereadora quebradeira de coco do Maranhão e do Brasil.

\section{Aspectos culturais}

Quando dizem "vamos quebrar a corrente do machismo e do poder" (AS ENCANTADEIRAS, 2014, p. 13), mostram a ampla dimensão de suas aspirações. À medida que suas organizações se fortalecem, igualmente se fortifica sua identidade, pois os conflitos que estão inseridas envolvem também uma disputa de narrativas, expressas em projetos sociais, culturais, econômicos. No canto intitulado "Oito de março" (AS ENCANTADEIRAS, 2014, p. 14) a primeira estrofe diz: "Tenho orgulho em ser mulher!/ Enfrento coco, enfrento a roça, enfrento a casa". Tem que ser "brasa viva" para abarcar tantas responsabilidades.

As mulheres são seres de capacidade, diz uma estrofe, é por isso que elas são necessárias nos espaços públicos e reivindicam um lugar merecido "nesta pátria varonil" (AS ENCANTADEIRAS, 2014, p. 15). Não tem sido fácil protagonizar nos espaços dominados por homens, sejam eles filhos, esposos, pais, lideres de associações e de sindicatos ou políticos. Para elas, é preciso romper com a segregação feminina para se conquistar a igualdade. Na música "Viva mulher brasileira" (AS ENCANTADEIRAS, 2014, p. 19) se perguntam quem traz a vida ao mundo, quem luta a vida inteira, quem cuida da familia e quem se organiza na comunidade.

Elas tiveram que enfrentar um grande obstáculo cultural: o medo. O medo do marido, do preconceito da comunidade, o medo da violência física dos fazendeiros, o medo de fracassar. O canto "Sem medo de ser mulher" (AS ENCANTADEIRAS, 2014, p. 30), diz que a luta não é só dos homens, mas é preciso deixar de ter medo de ser mulher. Para a canção, se as mulheres não se libertarem desse sentimento negativo, desse senso de inferioridade, o movimento não terá a mesma força.

Antes de assumirem papel importante nos movimentos sociais no Maranhão, eram apenas agentes sem rosto e sem razão, conforme mostra um verso (AS ENCANTADEIRAS, 2014, p. 31): "Ninguém escuta meu grito,/ Desconhecem meu sufoco./ Escondida lá na mata,/ Com fome, quebrando o coco". Outra estrofe lembra das infâncias perdidas nos babaçuais, "o machado é meu brinquedo/ cortando minha esperança". Muitas quebradeiras estão presas aos donos de terra, aos compradores de coco e a uma vida de pobreza e de sofrimento.

Apesar de a quebra do coco ser um trabalho árduo, por causar dores nas costas, devido ao longo tempo sentadas; causar cortes nas mãos e dedos, às vezes amputação; o ofício em si não 
é o pior, aos olhos de muitas dessas mulheres. $\mathrm{O}$ que torna a situação pior são as duras condições de trabalho em um contexto de falta de acesso aos babaçuais, baixo preço da amêndoa e de outros subprodutos por causa de atravessadores. Além disso, a falta de organização dessa cadeia produtiva em favor das próprias quebradeiras. Em algumas regiões, elas conseguiram se estabelecer em associações e cooperativas para organizar a produção, mas a maior parte das quebradeiras vive dispersa e sem grandes oportunidades.

Quando elas estão organizadas ou com essa perspectiva, sua concepção do trabalho ganha outro sentido. Na canção "Eu sou feliz quebrando coco" (AS ENCANTADEIRAS, 2014, p. 38), está expresso o sentimento positivo com a profissão. Mas alerta: "se ficar aqui parada, nada vamos conseguir". Nesse sentido, o ofício de quebrar coco ganha valor na esfera coletiva, protagonizada por mulheres, de acordo com sua identidade.

Umas das características das lutas femininas nos cocais, além de um perfil mais pacífico, é a proposta de preservação do ambiente. As quebradeiras aceitaram a pauta do acesso à terra no lugar de sua aquisição, como reivindicam os trabalhadores rurais, isso modifica a dinâmica dos conflitos e das reivindicações. Ao colocarem o debate ambiental em pauta, surgiram mudanças no debate político.

Preservar as florestas implica menos capim, menos pecuária extensiva, menos fogo nos cocais. Essas premissas levam ao fortalecimento do trabalho extrativista e sua organização sociopolítica. A narrativa da preservação ganhou força e trouxe consigo mudanças de valores no âmbito coletivo. Sem a participação das quebradeiras de coco do Maranhão e de outros estados, isso não teria ocorrido da mesma maneira.

A primeira canção do livro O xote das quebradeiras de coco (AS ENCANTADEIRAS, 2014, p. 8-9), traz a mensagem para não derrubar a palmeira. Para elas, a pauta ambiental surgiu da necessidade de sobrevivência. A canção "Ó liberdade" (AS ENCANTADEIRAS, 2014, p. 16) conclama as mulheres a lutarem juntas pelo ambiente, pois é do coco que elas levam o pão à mesa. Derrubar os palmeirais resulta em menos renda, menos tempero, alimento, remédios, artesanato e muitos outros subprodutos indispensáveis para vida de milhares de familias pobres do Maranhão.

Mesmo sem as terras, mesmo com as cercas e o gado, o acesso aos cocais já é uma vitória para elas. Elas têm outra concepção de posse, diferente dos fazendeiros. "Você é dono do gado, do açude e do curral,/ Mas não é dono do coco,/ nem também do coqueiral,/ Você corta boi de corte,/ mas não corte o palmeiral" (AS ENCANTADEIRAS, 2014, p. 21). Nessa concepção, os recursos naturais são de todos, não podem pertencer a alguns. Ao justificar a existência econômica, social e cultural do extrativismo do babaçu, elas pressionam donos de terras a preservar a floresta.

Essas mulheres perceberam ser mais fácil contornar as dificuldades da vida no trabalho conjunto. Os clubes de mães ou as câmaras municipais são resultados da necessidade de uma vida melhor para elas e suas comunidades. Elas aprenderam a criar Associações e fazer parcerias com outras organizações. Compreenderam a importância do convencimento, da narrativa vitoriosa, por isso deixaram de ser meras quebradeiras anônimas para serem agentes sociais, transformadoras da sociedade. Para isso, se reinventaram, se adaptaram, aprenderam novas linguagens politicas e apreenderam novas concepções de vida.

Contudo, as mulheres dos babaçuais vêm do campo, portanto, sua visão de mundo, sua cultura, seus valores, expressam essa atmosfera sociocultural. A árdua tarefa cotidiana de quebrar o coco é vista como algo ora negativo, ora positivo, a depender da mensagem que querem passar. Mas geralmente elas encaram seu "destino" com orgulho, seguem a tradição das mães e avós e repassam as suas descendentes.

O trabalho nos cocais pode ser mais árduo que o trabalho na roça. Às vezes, elas se levantam com o sol no horizonte, já levam seu almoço e voltam no final do dia. É comum passarem o dia inteiro na quebra do coco. Também o é carregar cofos ou cestos de palha na cabeça e andar longas distâncias sob sol e chuva. A canção "Pobre Rita" (AS ENCANTADEIRAS, 2014, p. 26), relata: 
Cabocla faceira

É aquela Rita

Muito dengosa, muito bonita

Quando ela passa de macete na mão

Machadinho amolado

Vestidinho de algodão

Vai quebrar o coco

Pra ganhar dinheiro

Pra compra arroz

Pra comprar feijão.

Pra comprar farinha, pra comprar o pão (2x).

[...].

Apesar dessas mulheres terem convivido com os movimentos sociais, terem se apropriado de narrativas politicas que defendem igualdade social, suas visões de mundo são pautadas, principalmente, pela própria vida comunitária e por valores religiosos. A maior parte dessas mulheres é católica, mesclada com crenças africanas e outros segmentos religiosos.

Tanto as que são participantes ativas nos movimentos sociais, quanto aquelas mais distantes, têm a crença política em um mundo melhor, mas pode-se afirmar que essa certeza é menos pela leitura política que religiosa, pois creem em um deus bondoso, preocupado com os oprimidos. Diz uma canção (AS ENCANTADEIRAS, 2014, p. 10): "Confiando em Cristo Rei, que nasceu lá em Belém/ E morreu crucificado, porque nos queria bem/ Confiando em seu amor, se reclama até a doutor,/ Mas nossos direitos vêm!". Ainda que os fazendeiros tenham a terra, a canção alerta os opressores e lembra que essa vida é curta e ao final dela não há diferença entre ricos e pobres. "Cuidado com teu mistério!/ Um dia no cemitério, nossa carne se mistura!" (AS ENCANTADEIRAS, 2014, p. 10). Lembra, ainda, que na morte, a morada é a cova e o verme, a única companhia.

A riqueza não servirá na outra vida e todos aqueles que oprimiram os pobres prestarão contas de sua avareza. "Quero ver tua defesa, onde está tua riqueza/ Que comprava o mundo inteiro?". Essa é uma concepção corrente em um catolicismo mais tradicional, especialmente ligado aos movimentos sociais. Tudo o que fazemos de ruim aos outros, receberemos em dobro, diz um verso, assim como a morte é certa, a justiça divina também não falha.

\section{Considerações finais}

Esse é parte do universo econômico, social, politica e cultural dessas trabalhadoras extrativistas. Por meio de cantos como estes aqui destacados, elas promulgam suas percepções sobre o mundo nas esferas coletiva e individual. A arte literária é capaz de tornar lúdica uma realidade dura, marcada pela pobreza e pela violência em distintas esferas, da mesma forma, ela também pode expressar, de maneira contundente, a saga de lutas antigas, que persistem à medida que as injustiças sociais permanecem.

Por meio dessas canções, foi possivel ter uma ideia dos aspectos visiveis das lutas dessas mulheres por uma vida melhor. Mais que isso, foi possivel percorrer nas entrelinhas e encontrar anseios que vão além de seus combates políticos, ao mostrar aspectos peculiares, únicos, dessas mulheres sobre a vida pessoal e em comunidade. A maneira como elas enxergam a política e a própria vida, está diretamente ligada à relação com a natureza e à religiosidade e isso leva a um modo singular de viver e de reagir diante das tensões sociais.

O fato de essas mulheres serem fiéis as suas crenças e superstições, muitas vezes acima de concepções políticas formais, não diminui a importância de seu aprendizado nos movimentos sociais, pelo contrário, aumenta seu valor. Elas apenas ressignificam novos aprendizados de acordo com suas concepções culturais. Esse saber único atente a necessidades também únicas e mostra que o mundo poder ser construido à imagem e à semelhança de cada sociedade.

Os versos compilados nesse livro de cantos são só uma amostra de uma realidade muito mais profunda e rica. Mesmo assim, é possivel extrair algumas reflexões sobre esses grupos de mulheres que têm ganhado notoriedade em diversas regiões. É possivel colher fragmentos que revelam suas relações sociais não apenas no âmbito coletivo. Ainda que muito mais poderia 
ter sido revelado, o que se viu aqui mostra quão complexo e dinâmico poder ser um conjunto de pessoas que sonham em remodelar o mundo em seu favor, especialmente quando esse grupo é composto por quebradeiras de coco babaçu.

\section{Referências}

ALMEIDA, Alfredo Wagner Berno de. (org.). Economia do Babaçu: Levantamento preliminar de dados. São Luis: MIQCB, 2000.

ANTUNES, Marta. As guardiãs da floresta do babaçu e o tortuoso caminho do empoderamento. In: WOORTMANN, Ellen F.; MENACHE, Renata; HEREDIA, Beatriz (org.). NEAD Especial. Brasilia: MDA, IICA, 2006.

AYRES JÚNIOR, José Costa. A organização das quebradeiras de coco babaçu e a refuncionalização de um espaço regional na Microrregião do Médio Mearim Maranhense. 2007. 186 f. Dissertação (Mestrado em Geografia) - Pós-Graduação em Geografia, Universidade Federal de Santa Catarina, Florianópolis, 2007.

AS ENCANTADEIRAS. Canto e encanto nos babaçuais. Músicas sob domínio popular selecionadas por "As Encantadeiras". [S. I.]: AS ENCANTADEIRAS; AMTR; MIQCB; ASSEMA; NCADR-UFPA, 2014. Disponivel em: http:// www.asmubip.org.br/wp-content/uploads/2016/04/ livro-quebradeiras-de-coco-babacu.pdf. Acesso em: 1 ago. 82017

BARBIERI, Ana Linhares Cavalcante. As tendências ao desenvolvimento sustentável no manejo do babaçu pelas comunidades rurais do estado do Maranhão. 2004. $114 \mathrm{f}$. Dissertação (Mestrado em Economia) - Pós-Graduação em Economia, Universidade Federal de Pernambuco, Recife, 2004

BARBOSA, Viviane de Oliveira. Histórias de trabalhadores rurais no Maranhão: Gênero, Identidades e Mobilização. In: XIX ENCONTRO REGIONAL DE HISTÓRIA: PODER, VIOLÊNCIA E EXCLUSÃO, São Paulo. Anais [...]. São Paulo: ANPUH/USP, 2008. p. 1-13.

DE CERTEAU, Michel. A escrita da História. 2. ed. Rio de Janeiro: Forense Universitária, 2002.

GINZBURG, Carlo. Mitos, emblemas e sinais: morfologia e história. São Paulo: Companhia das Letras, 1989.

GINZBURG, Carlo. O fio e os rastros: Verdadeiro, falso, fictício. São Paulo: Companhia das Letras, 2007.

\section{Raimundo Lima dos Santos}

Doutor em História pela Universidade Federal de Minas Gerais (UFMG), em Belo Horizonte, MG, Brasil; mestre pela Universidade Fede-ral de Goiás (UFG), em Goiânia, GO, Brasil; graduado pela Universidade Estadual do Maranhão (UEMA), em Imperatriz, MA, Brasil. Professor de História da América da Universidade Estadual da Região Tocantina do Maranhão (UEMASUL), em Imperatriz, MA, Brasil.

\section{Endereço para correspondência}

Raimundo Lima dos Santos

Universidade Estadual da Região Tocantina do Maranhão

Rua Godofredo Viana, 1300

Centro, 659000-000

Imperatriz, MA, Brasil

Os textos deste artigo foram revisados pela Poá Comunicação e submetidos para validação do autor antes da publicação. 